\title{
Genotipagem do citomegalovirus humano para pesquisa de resistência primária aos antivirais em transplantados renais
}

\section{Genotyping of human cytomegalovirus for antiviral primary resistance researches in kidney transplantation}

Emerson Carraro'; Celso Fransisco Hernandes Granato ${ }^{2}$

\begin{abstract}
unitermos resumo
Citomegalovirus

O objetivo do estudo foi investigar a ocorrência de cepas de citomegalovírus humano (HCMV) com

Antiviral resistência primária aos antivirais utilizados na terapêutica de pacientes transplantados renais. Para isso empregou-se um método de triagem por reação em cadeia de polimerase (PCR) e polimorfismo de Resistência tamanho de fragmentos de restrição (RFLP) capaz de detectar mutações específicas nos genes UL97 e UL97 UL54 relacionadas com resistência antiviral. Foram coletadas amostras (sangue, saliva e urina) de 20 pacientes transplantados renais no momento do diagnóstico da infecção pelo HCMV e sem terapia

UL54 antiviral prévia. Embora não tenham sido encontradas cepas de HCMV com nenhuma das mutações RFLP estudadas, a metodologia empregada demonstrou-se rápida e eficaz na análise dos genes virais das diferentes amostras testadas. A ausência de resistência primária no presente estudo não descarta a possibilidade de esse evento ocorrer futuramente no Brasil, uma vez que o emprego das drogas antivirais tem se disseminado em todo o mundo. Sugerimos, então, a aplicação da metodologia de PCR/RFLP na investigação de resistência do HCMV aos antivirais.
\end{abstract}

\section{abstract}

The aim of this study was to detect by PCR/RFLP HCMV strains containing specific UL97 or UL54 mutation in patients without previous therapy. Samples from 20 renal transplant recipients with HCMV infection at the moment of the diagnosis. From all the patients blood, saliva and urine samples were collected to investigate the possible occurrence of distinct mutations in different body sites. Although no HCMV strains with mutations conferring drug resistance were detected, the PCR/RFLP methodology was considered an adequate and practical tool to detect alterations in viral genes from different body fluids. The absence of drug resistant viral strains in the analyzed samples do not preclude its appearance in the near future, since the use of antiviral drugs in this setting is more widespread in the recent years. We suggest a periodic evaluation of the sensitivity pattern to antiviral drugs in order to monitor its occurrence. key words

Cytomegalovirus

Antiviral

Resistance

UL97

UL54

RFLP

1. Mestre em Ciências das Doenças Infecciosas e Parasitárias.

2. Professor-doutor da dis

Trabalho realizado no laboratório de virologia da Dipa do Departamento de Medicina da Unifesp.

Auxilio financeiro da Fundação de Amparo à Pesquisa do Estado de São Paulo (Fapesp) (99/09324-4).

Baseado na tese de mestrado Caracterização Cenotipica do Citomegalovírus Humano em Pacientes Transplantados Renais, 2001, Unifesp.

Apresentado no $36^{\circ}$ Congresso Brasileiro de Patologia Clínica e Medicina Laboratorial em São Paulo, 2002. 
A estratégia mais aplicada para a redução da morbidade e da mortalidade resultantes da infecção pelo citomegalovírus humano (HCMV) em pacientes imunossuprimidos envolve terapia prolongada ou extensa profilaxia. Ambos os casos consistem em risco potencial para a emergência de resistência a antivirais específicos. Por sua vez, a resistência a estes medicamentos resulta em falha terapêutica com conseqüente progressão da doença ${ }^{(13)}$.

Os agentes antivirais licenciados para o tratamento do HCMV, entre eles ganciclovir (Cymevene ${ }^{\circledast}$, Ganciclovir ${ }^{\circledR}$ e Ganyclov $\left.{ }^{\circledR}\right)$, foscarnet $\left(\right.$ Foscavir $\left.^{\circledR}\right)$ e cidofovir $\left(\text { Vistide }^{\circledR}\right)^{(2)}$, agem inibindo especificamente a síntese de DNA viral pela DNA-polimerase. Vários isolados de HCMV resistentes aos antivirais apresentam deleções ou substituições na seqüência de aminoácidos das regiões conservadas do gene UL97, codificante da fosfotransferase. Esta mutação resulta na diminuição da capacidade de fosforilação do ganciclovir na célula infectada e, conseqüentemente, ausência da síntese de ganciclovir trifosfato, que é a forma ativa da droga. Outros casos de resistência do HCMV aos antivirais devem-se a mutações na região UL54, codificadora da DNA-polimerase, responsável pela replicação viral. Nesse caso, ocorrem mutações pontuais nas regiões mais conservadas do gene UL54 que estão envolvidas no reconhecimento do substrato pela enzima, resultando na diminuição da afinidade pelo antiviral. A resistência ao ganciclovir pela mutação no gene UL54 é menos freqüente e, quando ocorre, geralmente está associada a mais de uma mutação em UL97, resultando em aumento na resistência ao ganciclovir e também resistência cruzada ao foscarnet e ao $\operatorname{cidofovir}^{(9,18)}$.

Naqueles casos em que ocorre apenas mutação no gene UL97, a substituição de ganciclovir pelo foscarnet tem demonstrado bons resultados, muito embora os efeitos colaterais possam limitar seu uso ${ }^{(1,4,19,20)}$. Desse modo, tornou-se mais evidente a importância do emprego de testes de suscetibilidade antiviral no acompanhamento da terapia anti-HCMV, servindo como indicador da estratégia terapêutica ${ }^{(12)}$. Recentemente, relatos sobre a ocorrência de infecções por cepas de HCMV com resistência aos antivirais antes da instituição da terapia ${ }^{(15)}$, ou logo após seu início(11, 26), indicam a aquisição de cepas com resistência primária. A partir disso, ressaltou-se a necessidade de detecção da resistência viral de forma rápida, um problema para as metodologias fenotípicas de suscetibilidade antiviral que dependem do cultivo de HCMV ou para o complexo seqüenciamento genético.

Com o objetivo de investigar a ocorrência de cepas de HCMV com resistência primária aos antivirais utilizados na terapêutica de pacientes transplantados renais, neste estudo empregou-se a técnica de genotipagem por reação em cadeia da polimerase (polymerase chain reaction - PCR) seguida de restrição enzimática (restriction fragment length polymorfism - RFLP) dos genes UL97 e UL54, para detectar mutações específicas relacionadas à resistência. As amostras utilizadas foram distintas em sangue, saliva e urina, para se aferir a possibilidade de usar diversos fluidos biológicos na análise de resistência.

Para isso foram incluídos 20 receptores de transplante renal atendidos consecutivamente no Hospital do Rim e Hipertensão da Universidade Federal de São Paulo (Unifesp), os quais desenvolveram infecção por HCMV. Para confirmação do diagnóstico foi utilizado o ensaio de antigenemia realizado na rotina do laboratório de virologia da disciplina de Doenças Infecciosas e Parasitárias (Dipa/Unifesp), seguindo recomendações da literatura ${ }^{(25)}$. Como critérios de inclusão foram adotados o resultado na antigenemia superior a dez células positivas $/ 2 \times 10^{5}$ leucócitos e a ausência de terapia antiviral prévia específica para HCMV. Simultaneamente foram coletadas amostras de urina e saliva, obtendo-se um total de 60 amostras (20 sangues, 20 urinas e 20 salivas), que foram estocadas a $-20^{\circ} \mathrm{C}$.

A extração do DNA viral foi feita a partir dos polimorfonucleares extraídos para o ensaio de antigenemia (amostras de sangue total com EDTA). Cada amostra foi centrifugada com $2 \mathrm{ml}$ de tampão de lavagem (Tris- $\mathrm{HCl}$ $10 \mathrm{mM} \mathrm{pH} \mathrm{7,6,} \mathrm{KCl} 10 \mathrm{mM}, \mathrm{MgCl}_{2} 10 \mathrm{mM}$, EDTA 20mM) por $5 \mathrm{~min} / 2.000 \mathrm{~g}$. Ao precipitado foram adicionados $800 \mu \mathrm{l}$ de tampão de lise (Tris- $\mathrm{HCl} 10 \mathrm{mM} \mathrm{pH} \mathrm{7,6,} \mathrm{KCl}$ $10 \mathrm{mM}, \mathrm{MgCl}_{2} 20 \mathrm{mM}$, EDTA $20 \mathrm{mM}, \mathrm{NaCl} 0,4 \mathrm{M}, 25 \mu \mathrm{l}$ SDS $20 \%$ ) e incubado por $10 \mathrm{~min} / 55^{\circ} \mathrm{C}$. Seguindo, $300 \mu \mathrm{L}$ de $\mathrm{NaCl} 5 \mathrm{M}$ foram adicionados e a mistura, centrifugada por $20 \mathrm{~min} / 10.000 \mathrm{~g}$. Por fim, o DNA foi precipitado com

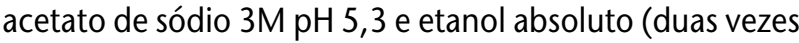
o volume) para depois ser ressuspendido em água mili-Q ${ }^{\circledR}$. A purificação da urina foi feita pela adição de $250 \mu \mathrm{l}$ da amostra ao mesmo volume do tampão de lise suplementado com proteinase $\mathrm{K}(0,2 \mathrm{mg} / \mathrm{ml})$, seguida de incubação $\left(55^{\circ} \mathrm{C}, 60\right.$ minutos) e inativação $\left(95^{\circ} \mathrm{C}, 10\right.$ minutos). A saliva foi usada diretamente para amplificação, conforme descrito anteriormente ${ }^{(5)}$.

Foi realizado nested-PCR em todas as amostras para se obter maiores sensibilidade e especificidade na detecção do HCMV. A primeira região estudada para verificar mutações que conferem resistência ao tratamento foi a do gene UL97 (códons 418-708), utilizando-se uma primeira reação com os iniciadores CPT0 e CPT2096, que geraram 
um fragmento de 2096pb, seguida por uma segunda reação com os iniciadores UL1088 e UL1619, que amplificaram um fragmento de $531 \mathrm{pb}^{(3)}$. Para analisar mutações na outra região (UL54) relacionada com resistência ao tratamento, foi amplificado um fragmento de $2748 \mathrm{pb}$ do gene UL54, utilizando-se os iniciadores pol1303 e pol4051 (24). Na segunda amplificação foram utilizados os iniciadores pol1474 e pol2536 $6^{(14)}$. Para cada reação foram incluídos um controle positivo (cepa padrão AD169) e um controle negativo (água obtida de Mili-Q ${ }^{\circledR}$ ), sendo cada reação confirmada pela visualização de bandas em gel de agarose a $2 \%$ impregnado com brometo de etídio. Através da digestão dos produtos amplificados nas PCRs com as endonucleases de restrição Nlalll, Alul, Hhal, Msel, Taql, Mspl e Haell objetivou-se identificar, pelo perfil de restrição obtido(6), as mutações mais freqüentemente descritas (M460V, H520Q, A594V, A594T, L595F, L595S, V715M e T700A), conforme revisado recentemente ${ }^{(16)}$.

Os 20 receptores de transplante renal selecionados para o estudo apresentaram em média 68,3 células positivas no ensaio de antigenemia para o HCMV, com uma variação de 11 a 416 células positivas (mediana de 41,5 células positivas). A infecção ocorreu no dia 47 após o transplante. Os pacientes tinham, em média, 42,5 anos de idade, igualmente distribuídos entre os sexos. O quadro clínico apresentado foi inespecífico de febre isolada ( $80 \%$ ) ou acompanhada de leucopenia, sendo que um paciente apresentou quadro com tosse e outro, abdome agudo. Todos os pacientes incluídos nesse estudo, após o diagnóstico, receberam terapia com ganciclovir (mediana de 21 dias de duração) e responderam bem, negativando a antigenemia.

Nenhuma das 60 amostras testadas genotipicamente apresentou quaisquer das mutações relacionadas à resistência pesquisadas no presente estudo. No entanto a metodologia empregada de genotipagem por PCR/RFLP confirmou a rapidez na análise da suscetibilidade antiviral de isolados clínicos de HCMV. Apesar da ausência de resistência, a adaptação das metodologias descritas por diferentes autores mostrouse reprodutível, inclusive permitindo a genotipagem viral dos diferentes sítios corpóreos estudados, uma vez que os resultados foram iguais para as diferentes amostras clínicas de um mesmo paciente.

Como todos os pacientes responderam bem à terapêutica, a possibilidade de falha na detecção de resistência por limitação da metodologia empregada é bastante pequena. No entanto deve-se ressaltar a limitação da técnica de PCR/RFLP, que só pode detectar mutações já descritas anteriormente. No caso da genotipagem do gene UL97, o ensaio é considerado ótimo para a triagem de cepas resistentes, pois cerca de $94 \%$ dos casos de resistência clínica ao ganciclovir apresentam pelo menos uma mutação nesse gene ${ }^{(15)}$, além de permitir sua deteç̧ão precocemente no acompanhamento de terapias prolongadas ${ }^{(22)}$. O nível de detecção de mutações no gene UL97 pela técnica de PCR/RFLP é superior a $90 \%{ }^{(8,14)}$. No presente estudo foram pesquisadas mutações que correspondem a cerca de $80 \%$ dos casos de resistência por mutação no gene UL97 do HCMV descritos na literatura, que incluem os códons 460 , 520 e $591-596^{(7)}$, o que fortalece o resultado encontrado de ausência de resistência primária nesses pacientes transplantados renais.

Quanto à possível diferença de distribuição de mutações entre os sítios corpóreos, o presente estudo não pode ser conclusivo devido à não-detecção de resistência. No entanto a literatura sugere que a resistência ao ganciclovir pode resultar em duas populações virais: uma de origem provável no órgão transplantado e a outra de transfusões de sangue, sendo esta prevalente e mutante ${ }^{(1)}$. Estes resultados foram confirmados em vários grupos de imunossuprimidos em que se detectou a cepa de HCMV mutante inicialmente no órgão envolvido para depois atingir outros sítios ${ }^{(17)}$.

Conforme indicado pela literatura, a seleção in vivo de variantes virais com mutações em UL97, mas com baixo nível de resistência ao antiviral, resulta em acúmulo de mutações em UL54 e, como o tempo de terapia é prolongado, gera uma subpopulação viral com dupla mutação e de alto nível de resistência ${ }^{(10,23)}$. Por isso a resistência clínica aos antivirais por mutação na DNA-polimerase do HCMV é pouco freqüente, sendo sugerida a necessidade da presença de mais de uma mutação no gene UL97 ${ }^{(21)}$. Neste estudo os pacientes não receberam tratamento ou profilaxia prévia, tornando-se uma população com pequena possibilidade de apresentar mutações no gene UL54. Com isso este trabalho tem a intenção de avaliar a possibilidade de um novo teste de triagem por PCR/RFLP também para mutações na DNApolimerase viral, uma vez que esta detecção, atualmente depende do seqüenciamento genético ${ }^{(16,18)}$.

O presente estudo não detectou nenhuma cepa de HCMV com as mutações de maior incidência nos genes UL97 e UL54 associadas com resistência aos antivirais. Esse resultado contribui para a provável idéia da inexistência de resistência primária aos antivirais na terapia com $\mathrm{HCMV}$ em receptores de transplante renal em São Paulo. Entretanto, por se tratar de algo pouco investigado, não podemos descartar a possibilidade de esse evento não estar sendo detectado em outros serviços, bem como a possibilidade 
de ocorrer futuramente no país, uma vez que a resistência aos antivirais é um fato emergente em diferentes partes do mundo. Portanto sugerimos a contínua aplicação da metodologia de PCR/RFLP, principalmente para o gene UL97, na investigação de resistência primária do HCMV aos antivirais.

\section{Referências}

I. BALDANTI, F. et al. Ganciclovir resistance as a result of oral ganciclovir in a heart transplant recipient with multiple human cytomegalovirus strains in blood. Transplantation, v. 66, n. 3, p. 324-9, 1998.

2. BALFOUR JR., H. H. Antiviral drugs. N Engl J Med, v. 340, n. 16 , p. 1255-68, 1999.

3. BOIVIN, G. et al. Detection of ganciclovir resistance mutations quantitation of cytomegalovirus (CMV) DNA in leukocytes of patients with fatal disseminated CMV disease.J Infect Dis, v. 173, n. 3, p. 523-8, 1996.

4. BOWEN, E. F. et al. Quantitative changes in cytomegalovirus DNAemia and genetic analysis of the UL97 and UL54 genes in Aids patients receiving cidofovir following ganciclovir therapy.J Med Virol, v. 58, n. 4, p. 402-7, 1999.

5. CARRARO, E.; GRANATO, C. F. H. Single human cytomegalovirus gB genotype shed in multiple sites at the time of diagnosis in renal transplant recipients. J Med Virol, v. 70, n. 2, p. 240-3, 2003.

6. CHOU, S.W.; DENNISON, K. M. Analysis of interstrain variation in cytomegalovirus glycoprotein B sequences encoding neutralization-related epitopes. J Infect Dis, v. 163, n. 6, p. |229-34, 199|.

7. CHOU, S. et al. Frequency of UL97 phosphotransferase mutations related to ganciclovir resistance in clinical cytomegalovirus isolates. J Infect Dis, v. I72, n. I, p. 239-42, 1995.

8. CHOU, S. et al. Analysis of the UL97 phosphotransferase coding sequence in clinical cytomegalovirus isolates and identification of mutations conferring ganciclovir resistance. J Infect Dis, v. I7I, n. 3, p. 576-83, 1995.

9. $\mathrm{CHOU}$, S. et al. Cytomegalovirus UL97 phosphotransferase mutations that affect susceptibility to gangiclovir. Infect Dis, v. 185, p. 162-9, 2002.

10. DREW,W. L. Ganciclovir resistance: a matter of time and titre. Lancet, v. 356, p. 609-10, 2000.

I I. ECKLE, T. et al. Drug-resistant human cytomegalovirus infection in children after allergenic stem cell transplantation may have different clinical outcomes. Blood, v. 96, n. 9, 3286-9, 2000.

12. EMERY, V. C. Progress in understanding cytomegalovirus drug resistance. J Clin Virol, v. 2 I, n. 3, p. 223-8, 2001.

13. ERICE, A. et al. Progressive disease due to ganciclovir-resistant cytomegalovirus in immunocompromised patients. N Engl J Med, v. 320, n. 5, p. 289-93, 1989.

14. ERICE, A. et al. Antiviral susceptibilities and analysis of UL97 and DNA polymerase sequences of clinical cytomegalovirus isolates from immunocompromised patients. J Infect Dis, v. 175, n. 5, p. 1087-92, 1997.

I5. ERICE,A. Resistance of human cytomegalovirus to antiviral drugs. Clin Microbiol Rev, v. 12, n. 2, p. 286-97, 1999.
16. GILBERT, C. et al. Resistance of herpesviruses to antiviral drugs: clinical impacts and molecular mechanisms. Drugs Res Updates, v. 5, p. 88- I 14, 2002.

17. LI, W. et al. Cytomegalovirus UL97 and glycoprotein B (gB) sequences in tissues from immunocompromised patients with ganciclovir-resistant virus infection. Scand J Infect Dis, v. 3I, n. 6, p. 549-53, 1999.

18. LIMAYE, A. J. Ganciclovir-resistant cytomegalovirus in organ transplant recipients. Clin Infect Dis, v. 35, p. 866-72, 2002.

19. MANSO, J.V. et al. Ganciclovir resistance in a heart transplant recipient infected by cytomegalovirus. Int J Cardiol, v. 7 I, n. I, p. 97-8, 1999.

20. MYLONAKIS, E. et al. Combination on antiviral therapy for ganciclovir-resistant cytomegalovirus infection in solid-organ transplant recipient. Clin Infect Dis, v. 34, p. 1337-41, 2002.

21. PEREZ, J. L. Resistance to antivirals in human cytomegalovirus: mechanisms and clinical significance. Microbiologia, v. I3, n. 3, p. 343-52, 1997.

22. PRIX, L. et al. Comprehensive restriction analysis of the UL97 region allows early detection of ganciclovir-resistant human cytomegalovirus in an immunocompromised child. J Infect Dis, v. I80, n. 2, p. 491-5, 1999.

23. SMITH, I. L. et al. A High-level resistance of cytomegalovirus to ganciclovir is associated with alterations in both the UL97 and DNA polymerase genes. I Infect Dis, v. 176, n. I, p. 6977, 1997.

24. SULLIVAN,V. et al.A point mutation in the human cytomegalovirus DNA polymerase gene confers resistance to ganciclovir and phosphonylmethoxyalkyl derivatives. Antimicrob Agents Chemother, v. 37, n. I, p. 19-25, 1993.

25. THE, T. H. et al. The cytomegalovirus antigenemia assay: a plea for standardization. Scand. J Infect Dis Suppl, v. 99, p. 25-9, 1995.

26.WOLF, D. G. et al. Early emergence of ganciclovir-resistant human cytomegalovirus strains in children with primary combined immunodeficiency.J Infect Dis, v. I78, n. 2, p. 535-8, 1998.
Endereço para correspondência

Emerson Carraro Rua Pedro de Toledo 781/15ㅇandar/frente Vila Clementino CEP 04039-032 - São Paulo-SP Telefax: (11) 5081-5394 e-mail: emersoncarraro@bol.com.br 